LEUSIN, Rodrigo Westphalen; CADEMARTORI, Sérgio. Os direitos fundamentais nas relações privadas: da eficácia à teoria garantista de Luigi Ferrajoli. Revista Eletrônica Direito e Política, Programa de Pós-Graduação Stricto Sensu em Ciência Jurídica da UNIVALI, Itajaí, v.10, n.2, $1^{\circ}$ quadrimestre de 2015. Disponível em: www.univali.br/direitoepolitica - ISSN 1980-7791.

\title{
OS DIREITOS FUNDAMENTAIS NAS RELAÇÕES PRIVADAS: DA EFICÁCIA À TEORIA GARANTISTA DE LUIGI FERRAJOLI
}

\author{
FUNDAMENTAL RIGHTS IN THE PRIVATE RELATIONS: FROM \\ EFFECTIVENESS TO THE LUIGI FERRAJOLI'S THEORY OF THE GARANTISM
}

\author{
Rodrigo Westphalen Leusin ${ }^{1}$ \\ Sergio Cademartori ${ }^{2}$
}

SUMÁRIO: Introdução. 1 Da ONU ao Código Civil. 2 Eficácias e Garantismo. 3 As Cláusulas Gerais: Caráter Complementar. 4 Direitos Fundamentais Liberais: Suficiência Institucional e Legal para a sua Aplicação Mediante Interpretação. 5 Direitos Fundamentais de Cariz Social: Insuficiência Institucional e de Garantia para sua Aplicação Mediante Interpretação. 6 Recuperação do Jusnaturalismo ou Consagração do Positivismo via Garantismo para Efetivar Direitos Fundamentais. Considerações finais. Referências das fontes citadas.

RESUMO: O artigo apresenta um panorama a respeito da eficácia e aplicação dos direitos fundamentais às relações privadas, buscando uma solução não excludente de técnicas e doutrinas que podem ser complementares. Para tanto, faz-se uma breve abordagem histórica da recepção pelos ordenamentos civis das normas de direitos humanos, desde as instituições estabelecidas no $2 .^{\circ}$ pós guerra mundial, até a realidade civil-constitucional do Brasil. Opondo, não para excluir, mas para se complementar, teorias de juristas brasileiros e alemães, com Luigi Ferrajoli e sua teoria do garantismo, pretende-se evidenciar que a temática, ainda que exaustivamente abordada na doutrina europeia e latinoamericana, continua rica e fomentadora de ideais para o direito.

Palavras-chave: Direitos fundamentais; Garantismo; Eficácia; Positivismo; Neoconstitucionalismo.

\footnotetext{
1 Mestrando em Direito pelo PPGD/Unilasalle, cidade de Canoas/RS, Brasil, e-mail rwleusin@gmail.com

2 Professor do PPGD/Unilasalle, cidade de Canoas/RS, Brasil, e-mail scademartori@uol.com.br
} 
LEUSIN, Rodrigo Westphalen; CADEMARTORI, Sérgio. Os direitos fundamentais nas relações privadas: da eficácia à teoria garantista de Luigi Ferrajoli. Revista Eletrônica Direito e Política, Programa de Pós-Graduação Stricto Sensu em Ciência Jurídica da UNIVALI, Itajaí, v.10, n.2, $1^{\circ}$ quadrimestre de 2015. Disponível em: www.univali.br/direitoepolitica - ISSN 1980-7791.

ABSTRACT: The paper presents an overview regarding the effectiveness and implementation of fundamental rights to private relationships, seeking a nonexclusive solving techniques and doctrines that can be complementary. Therefore, it is an historical approach reception for civil systems of human rights standards, from the institutions established after the World War 2, to the civil and constitutional reality of Brazil. Opposing, not to exclude, but to complement other theories of Brazilian and German jurists, with Luigi Ferrajoli and his theory of garantism is intended to highlight that the theme, though thoroughly discussed in European and Latin American doctrine, still rich and creator in ideals to the Law.

Keywords: Fundamental rights; Garantism; Effectiveness; Positivism; Neoconstitutionalism.

\section{INTRODUÇÃO}

A ordem constitucional brasileira, a partir de 1988, motivou a transformação do direito privado, através da sua constitucionalização.

As premissas postas pela Constituição Federal de 1988 promoveu a superação da então clássica dicotomia direito público-direito privado, desfazendo-se a divisão existente entre o direito privado, voltado aos indivíduos, e o direito constitucional, voltado ao Estado ${ }^{3}$.

Exsurge dessa virada paradigmática a problemática da aplicação dos direitos fundamentais às relações particulares, revelando acintosamente a fragilidade conceitual dessa dicotomia, já que "Público e privado são, na unidade teleológica dos interesses universalizáveis, uma mesma e única realidade, nascida dos mesmos princípios e votada aos mesmos fins: um é a vida do outro" ${ }^{4}$.

Esse paradigma rompedor da discriminação dicotômica integra a Constituição ao ordenamento, permeando-o de seus princípios e regras, e unindo mundos que são dirigidos por uma mesma lógica, a fim de superar a falta de identidade moral entre ambos. E está no centro dessa reunião entre direito privado e direito

\footnotetext{
3 TEPEDINO, Gustavo. In: TEPEDINO, Gustavo e FACHIN, Luiz Edson (Orgs.). Diálogos sobre o Direito Civil - volume II, Rio de Janeiro: Renovar, 2008, p. 196.

${ }^{4}$ SARLET, Ingo Wolfgang. A Eficácia dos Direitos Fundamentais. 11. a edição. Porto Alegre: Editora Livraria do Advogado, 2012, p. 304.
} 
LEUSIN, Rodrigo Westphalen; CADEMARTORI, Sérgio. Os direitos fundamentais nas relações privadas: da eficácia à teoria garantista de Luigi Ferrajoli. Revista Eletrônica Direito e Política, Programa de Pós-Graduação Stricto Sensu em Ciência Jurídica da UNIVALI, Itajaí, v.10, n.2, $1^{\circ}$ quadrimestre de 2015. Disponível em: www.univali.br/direitoepolitica - ISSN 1980-7791.

constitucional o princípio da dignidade da pessoa humana como fundamento e objetivo dos diversos modos que os direitos fundamentais devem incidir sobre as relações privada ${ }^{5}$.

Entretanto, a complexidade da vida e a multiculturalidade da sociedade, bem como o desenvolvimento e avanços dos direitos em variadas dimensões humanas, consolidou nos textos constitucionais das democracias ocidentais direitos liberais e sociais que exigem sua ampla efetivação para a realização mínima da dignidade da pessoa humana.

Aos operadores do direito, em especial àqueles que trabalham com a aplicação das normas nos casos concreto, cabe a função fundamental de aplica-las para efetivar os direitos fundamentais de cariz liberal ou social nos casos da vida concreta. Nesse desiderato, diversas matizes doutrinárias são aplicadas, ou isoladamente, quando suficiente, ou ainda, mediante uma combinação de possibilidades.

O presente trabalho apresenta um comparativo incipiente sobre técnicas e teorias de aplicação e efetivação dos direitos fundamentais entre privados, com especial foco sobre a teoria garantista de Luigi Ferrajoli.

\section{DA ONU AO CÓDIGO CIVIL}

Os direitos fundamentais, a partir da consolidação da declaração universal dos direitos do homem pela ONU, em 1945, integram o renovado arcabouço constitucional das potências políticas e econômicas ocidentais após a 2. a guerra mundial, chegando aos países latino-americanos mais tardiamente, depois do fim das ditaduras militares que assolaram o subcontinente, em mais um dos seus sombrios períodos históricos.

A Constituição Brasileira de 1988 é um exemplo claro dessas circunstâncias. Todavia, a congregação e a afetação de todo o ordenamento jurídico pela sua

\footnotetext{
5 TEPEDINO, Gustavo. In: TEPEDINO, Gustavo e FACHIN, Luiz Edson (Orgs.). Diálogos sobre o
} Direito Civil - volume II, p. 196. 
LEUSIN, Rodrigo Westphalen; CADEMARTORI, Sérgio. Os direitos fundamentais nas relações privadas: da eficácia à teoria garantista de Luigi Ferrajoli. Revista Eletrônica Direito e Política, Programa de Pós-Graduação Stricto Sensu em Ciência Jurídica da UNIVALI, Itajaí, v.10, n.2, $1^{\circ}$ quadrimestre de 2015. Disponível em: www.univali.br/direitoepolitica - ISSN 1980-7791.

força normativa se pôs em andamento, afetando as diversas searas legais infraconstitucionais, mas, especialmente, o texto legal civilista, que se renova com o Código Civil de 2002.

Este vem recheado de cláusulas gerais, tanto como técnica formal, quanto como substância normativa, atendendo ao momento histórico estabelecido a partir da Constituição de 1988 e que corresponde à superação do modelo liberal do Estado de Direito, em direção a um modelo que reconsidere a posição, efetivação e garantia dos direitos sociais, na mesma medida em que são efetivados e garantidos os direitos liberais, tal como a liberdade e a propriedade.

A vinculação das relações privadas aos direitos fundamentais, especialmente quanto à efetividade dessa vinculação, é razão de estudo e suscita uma problemática no panorama jurídico brasileiro.

\section{O PROBLEMA DA EFICÁCIA E A PERSPECTIVA DO GARANTISMO}

São diversas as doutrinas que abordam a incidência no âmbito privado dos direitos fundamentais e elas se subdividem, de forma generalizante, a partir de duas modalidades de vinculação: direta e imediata ou indireta e mediata ${ }^{6}$.

No âmbito da eficácia mediata ou indireta, a partir dos estudos de Günther Durig", surge a ideia de que "o reconhecimento de uma eficácia direta no âmbito das relações entre particulares acabaria por gerar uma estatização do direito privado e um virtual esvaziamento da autonomia privada". Essa posição é a predominante no Tribunal Constitucional Alemão e, de modo perceptível, nos tribunais brasileiros igualmente. Aqui, a incidência da norma sobre o caso concreto depende da mediação legislativa, ou, em último caso, do juiz.

\footnotetext{
6 PAULINI, Melina e FACHIN, Luiz Edson. In: TEPEDINO, Gustavo e FACHIN, Luiz Edson (Orgs). Diálogos sobre o Direito Civil - volume II, p. 203.

7 Apud: SARLET, I. W. Direitos Fundamentais e Direito Privado: algumas considerações em torno da vinculação dos particulares aos direitos fundamentais. Porto Alegre: Livraria do Advogado, 2000, p. 123. A Constituição Concretizada.
} 
LEUSIN, Rodrigo Westphalen; CADEMARTORI, Sérgio. Os direitos fundamentais nas relações privadas: da eficácia à teoria garantista de Luigi Ferrajoli. Revista Eletrônica Direito e Política, Programa de Pós-Graduação Stricto Sensu em Ciência Jurídica da UNIVALI, Itajaí, v.10, n.2, $1^{\circ}$ quadrimestre de 2015. Disponível em: www.univali.br/direitoepolitica - ISSN 1980-7791.

Quanto à eficácia imediata ou direta, Nipperdey defende que os direitos fundamentais são diretamente aplicáveis sobre as relações privadas e permeando o ordenamento jurídico na íntegra, sem mediações ${ }^{8}$.

Todavia, diferentemente dessas posições, que ora invocam uma aplicação imediata, exigindo a intermediação de algum ator político (o legislador ou o juiz), ou desprezando a necessidade de intermediação legislativa (que se por um lado pode prejudicar a eficácia do direito, por outro reforça o caráter democrático do sistema), o jusfilósofo Luigi Ferrajoli apresenta, através de sua teoria garantista, outra opção.

Ferrajoli oferece a leitura garantista da constituição a fim de preservar e garantir, dentre outros conceitos fundamentais da democracia, como a separação dos poderes e a separação entre direito e moral, os direitos fundamentais nela previstos. As práticas judiciárias brasileiras inclinaram-se nos últimos anos para uma leitura tendencialmente neoconstitucionalista dos direitos consolidados na Constituição Federal de 1988, especialmente sobre aqueles nela insculpidos sob a forma de princípios, conforme essa mesma corrente denomina. Essa abordagem judicial, parece apontar para o enfraquecimento do caráter democrático do Estado de Direito Constitucional, tanto no seu aspecto formal, quanto especialmente ao material. No que tange especificamente à aplicação dos direitos fundamentais nas relações privadas, o comportamento do juiz neoconstitucionalista, adotando a perspectiva do realismo jurídico, é que vai determinar a sua aplicação efetiva, ou sua negação, no caso concreto.

O autor italiano aponta as consequências da divergência entre a previsão constitucional e as práticas legislativas, jurisdicionais ou as administrativas, que se resumem, simplificadamente, à ideia de tornar a constituição uma "simples referência, com mera função de mistificação ideológica" ${ }^{9}$. A partir dessa denúncia, explica o surgimento do garantismo como superação dessa ineficácia,

\footnotetext{
8 PAULINI, Melina e FACHIN, Luiz Edson. In: TEPEDINO, Gustavo e FACHIN, Luiz Edson (Orgs). Diálogos sobre o Direito Civil - volume II, p. 204.

${ }^{9}$ FERRAJOLI, Luigi. Direito e Razão: teoria do garantismo penal. Tradução: Ana Paula Zomer Sica, etc. São Paulo: Editora Revista dos Tribunais., 2 ed. São Paulo: Editora Revista dos Tribunais, 2006, p. 785.
} 
LEUSIN, Rodrigo Westphalen; CADEMARTORI, Sérgio. Os direitos fundamentais nas relações privadas: da eficácia à teoria garantista de Luigi Ferrajoli. Revista Eletrônica Direito e Política, Programa de Pós-Graduação Stricto Sensu em Ciência Jurídica da UNIVALI, Itajaí, v.10, n.2, $1^{\circ}$ quadrimestre de 2015. Disponível em: www.univali.br/direitoepolitica - ISSN 1980-7791.

atribuindo-Ihe três significados, que não se restringem a efeitos no campo do direito penal, pois são expansíveis a todos os campos do ordenamento.

Como um "modelo normativo de direito", pelo qual se poderá avaliar o grau de conformidade do ordenamento jurídico ordinário com a Constituição, ou seja, o nível de efetividade da norma superior, bem como examinar a existência de antinomias entre normas inferiores e seus princípios constitucionais ${ }^{10}$. No âmbito político visa a estabelecer tutelas que restrinjam a violência e a ampliem as liberdades. Na esfera jurídica funciona como um sistema que vincula a função punitiva do Estado para garantia dos direitos dos cidadãos.

Como uma "teoria jurídica da validade e da efetividade", o garantismo separa o "ser" e o "dever ser" no direito. Aqui o problema principal é a discrepância patológica entre modelos normativos (de tendência garantista) e as práticas operacionais (que tendem ao antigarantismo). Nesse sentido, essa divergência é interpretada como uma antinomia entre, de um lado, a validade e a não efetividade do modelo normativo e, de outro lado, a efetividade e invalidade da prática operacional correspondente ${ }^{11}$.

Já no terceiro significado atribuído, "garantismo" exprime uma filosofia política "que requer do direito e do Estado o ônus da justificação externa com base nos bens e interesses dos quais a tutela ou a garantia constituem a finalidade", isto é, nos dizeres de Sergio Cademartori, "um discurso normativo e uma prática coerentes com a tutela e garantia dos valores, bens e interesses que justificam a sua existência". Essa designação permite a separação, no ordenamento, entre ser e dever ser, o que, conforme Ferrajoli, é denominado como o "ponto de vista externo", pois ex parte populi, ou seja, é o aspecto essencialmente democrático da teoria; de outro lado, há ponto de vista interno, ex parte principis.

Nesses três significados, conjuntamente considerados (são conexos), estabelecese os contornos dos elementos da teoria geral do garantismo: o caráter vinculado do poder público no Estado de direito; a divergência entre validade e

${ }^{10}$ CADEMARTORI, Sergio. Estado de Direito e Legitimidade: Uma Abordagem Garantista. 2 ed. Campinas: Millennium Editora, 2006, p. 203.

${ }^{11}$ FERRAJOLI, Luigi. Direito e Razão: teoria do garantismo penal. p. 786. 
LEUSIN, Rodrigo Westphalen; CADEMARTORI, Sérgio. Os direitos fundamentais nas relações privadas: da eficácia à teoria garantista de Luigi Ferrajoli. Revista Eletrônica Direito e Política, Programa de Pós-Graduação Stricto Sensu em Ciência Jurídica da UNIVALI, Itajaí, v.10, n.2, $1^{\circ}$ quadrimestre de 2015. Disponível em: www.univali.br/direitoepolitica - ISSN 1980-7791.

vigor produzida pelos desníveis das normas e um respectivo grau de irredutibilidade de ilegitimidade jurídica das práticas normativas inferiores; a diferença entre o ponto de vista externo (ético-político) e o ponto de vista interno (jurídico) com a correspondente divergência entre justiça e validade; e, a autonomia e precedência do ponto de vista externo em relação ao interno, em um grau irredutível de ilegitimidade política com respeito àquele.

Conforme sintetiza Cademartori, tal teoria torna-se uma crítica das ideologias políticas, sejam jusnaturalistas ou ético-formalistas, que confundem a justiça com o direito e vice-versa, e das ideologias jurídicas, tanto normativistas quanto realistas, que confundem, no plano interno, a validade com a vigência, ou pelo contrário, a efetividade (ou eficácia) com a validade. E com Ferrajoli ${ }^{12}$, repisando, tem-se como principal pressuposto metodológico da teoria garantista a separação entre o direito e a moral e, mais em geral, entre o ser e dever ser. Ademais, é o reconhecimento da diferença entre normatividade e efetividade que permite realizar a correta análise dos fenômenos jurídicos, evitando a dupla falta, naturalista e normativa, da assunção dos fatos como valores, ou o contrário, dos valores como fatos.

\section{AS CLÁUSULAS GERAIS: CARÁTER COMPLEMENTAR}

Acreditava-se nos primeiros anos após a vigência do Código Civil de 2002, que tínhamos naquela norma um potencial transformador da realidade brasileira, inclusive para fins de efetivação do estado social previsto na Constituição de 1988.

Um dos instrumentos oferecidos pelo legislador aos operadores do direito, mais diretamente aos juízes, como já referido alhures, é a técnica da cláusula geral, prevista em diversos artigos do código civil, tais como o 421 e o 422, recurso considerado como oposição às doutrinas individualistas, à teoria geral do Direito

\footnotetext{
${ }^{12}$ FERRAJOLI, Luigi. Direito e Razão: teoria do garantismo penal. p. 788.
} 
LEUSIN, Rodrigo Westphalen; CADEMARTORI, Sérgio. Os direitos fundamentais nas relações privadas: da eficácia à teoria garantista de Luigi Ferrajoli. Revista Eletrônica Direito e Política, Programa de Pós-Graduação Stricto Sensu em Ciência Jurídica da UNIVALI, Itajaí, v.10, n.2, $1^{\circ}$ quadrimestre de 2015. Disponível em: www.univali.br/direitoepolitica - ISSN 1980-7791.

Civil modelada pelos ideais pandectistas, desagregados da atual realidade social e dos valores e princípios constitucionais positivados ${ }^{13}$.

A abertura do sistema era saudada e tratada como considerável instrumento para a efetivação de direitos fundamentais, em especial os sociais. Esse otimismo assentava-se em fundamentos propostos por autores alemães, v.g., Karl Larenz e Claus-Wilhelm Canaris, bem como por brasileiros, como Juarez Freitas, Luiz Edson Fachin, Judith Martins-Costa e Gustavo Tepedino.

Todavia, a dependência de um sistema de justiça coerente e lógico, inclusive em relação à democracia, demonstrou que a tarefa hercúlea de transformação social precisava, além de recursos para alcançar resultados práticos com soluções justificadas, também técnicas de aplicação das normas (fossem elas princípios ou regras), especialmente cuidando da discricionariedade e liberdade do juiz em escolher como abrir, fechar ou colmatar o sistema através de diferentes valores e princípios, mantendo sua estrutura de sistema conceitual.

Não se despreza, com isso, as potencialidades da abertura provocada pela aplicação da norma através da cláusula geral. Casos paradigmáticos que constituíram e constituem jurisprudência transformadora da realidade social, foram julgados mediante uso de técnicas de abertura ou flexibilização do sistema.

Gustavo Tepedino, enfrentando a matéria ${ }^{14}$, refere casos emblemáticos de tensão entre preceitos da atividade econômica privada e direitos fundamentais. O primeiro deles advém da França, da cidade de Morsang-sur-Orge, cujo prefeito interditou um espetáculo circense, por que considerou que o arremesso de um anão, pela plateia, de um lado ao outro do picadeiro, para mero entretenimento, configurava violação à dignidade do homem arremessado. A decisão do prefeito baseou-se no artigo 3.0 da Convenção Europeia de Salvaguarda dos Direitos do

\footnotetext{
${ }^{13}$ ARONNE, Ricardo. Por uma nova hermenêutica dos Direitos Reais limitados: das raízes aos fundamentos contemporâneos. Rio de Janeiro: Renovar, 2001. p. 35.

${ }^{14}$ TEPEDINO, Gustavo. In: TEPEDINO, Gustavo e FACHIN, Luiz Edson (Orgs). Diálogos sobre o Direito Civil - volume II, p. 69/70.
} 
LEUSIN, Rodrigo Westphalen; CADEMARTORI, Sérgio. Os direitos fundamentais nas relações privadas: da eficácia à teoria garantista de Luigi Ferrajoli. Revista Eletrônica Direito e Política, Programa de Pós-Graduação Stricto Sensu em Ciência Jurídica da UNIVALI, Itajaí, v.10, n.2, 10 quadrimestre de 2015. Disponível em: www.univali.br/direitoepolitica - ISSN 1980-7791.

Homem e das Liberdades Fundamentais, que consagra o princípio da dignidade da pessoa humana.

Todavia, o próprio homem opôs-se a decisão da prefeitura, atuando como litisconsorte da empresa interessada e recorreu ao Tribunal Administrativo francês. Nesse foro, o homem e a empresa tiveram êxito, porque o tribunal liberou a atividade, sob o pretexto de que a atividade não perturbava a "boa ordem, a tranquilidade ou a salubridade públicas", ou seja, a dignidade da pessoa humana não estaria inserida nos preceitos de ordem pública. O caso foi ao Conselho de Estado, que modificou a decisão, estabelecendo, finalmente, que "o respeito à dignidade da pessoa humana é um dos componentes da noção de ordem pública; e que a autoridade investida do poder de polícia municipal pode, mesmo na ausência de circunstâncias locais específicas, interditar um espetáculo atentatório à dignidade da pessoa humana".

Da mesma forma evolui a jurisprudência brasileira nos casos de mudança de sexo e alteração do registro civil das respectivas pessoas, que, ainda que tardiamente, passou a aceitar a alteração, enfrentando o descompasso existente entre a realidade fática e a legislativa.

Ainda casos referentes à bioética, reprodução assistida, informação na rede mundial de computadores, pululam na sociedade e nos tribunais, ficando à mercê do entendimento individual e discricionário de um juiz, para a sua solução.

No âmbito constitucional, quanto à proteção da pessoa humana, a cláusula geral de tutela fixada pela Constituição de 1988, nos artigos 1.0, III; 3.0, III, e 5.0, parágrafo 2.0, ainda carece de uma institucionalidade e regulamentação que garanta sua aplicação, pois não raramente passa despercebida pelos juízes, especialmente quando confrontados com casos que opõem direitos patrimoniais referentes à propriedade, família, empresa ou relações de consumo com direitos sociais, como moradia, alimentação e saúde.

Observe-se que os valores sociais e existenciais pretensamente tutelados pela cláusula geral em comento permanecem, no Brasil, submetidos ao segundo plano 
LEUSIN, Rodrigo Westphalen; CADEMARTORI, Sérgio. Os direitos fundamentais nas relações privadas: da eficácia à teoria garantista de Luigi Ferrajoli. Revista Eletrônica Direito e Política, Programa de Pós-Graduação Stricto Sensu em Ciência Jurídica da UNIVALI, Itajaí, v.10, n.2, $1^{\circ}$ quadrimestre de 2015. Disponível em: www.univali.br/direitoepolitica - ISSN 1980-7791.

normativo e político, pois não há para os direitos sociais as garantias que há para dos direitos liberais.

\section{DIREITOS FUNDAMENTAIS LIBERAIS: SUFICIÊNCIA INSTITUCIONAL E LEGAL PARA A SUA APLICAÇÃO MEDIANTE INTERPRETAÇÃO}

$\mathrm{Na}$ concepção liberal a constituição é o documento essencial da organização estatal, que visa a garantir a liberdade, através de um estatuto do poder. Esse estatuto é uma organização jurídica que além de estruturar, deve limitar o Poder do Estado ${ }^{15}$; essa, pode-se dizer, foi a grande conquista do liberalismo.

Juridicamente, a expressão máxima do Estado liberal está contida na declaração dos direitos do homem e do cidadão, de 1789. Nos ideais de John Locke, interesses burgueses são protegidos, tais como a liberdade, a propriedade, a segurança e a resistência à opressão (a crença liberal, portanto), ao lado da soberania (colhida dos ideais rousseauístas). Dele decorre o novo direito ocidental, estabelecido numa tríade, código civil, código penal e constituição formal, onde o Código Civil exerce papel preponderante ${ }^{16}$.

As garantias liberais ou negativas, que são as limitações atribuídas ao Estado de Direito pelo liberalismo, consistem, tão somente, nas garantias do indivíduo de não ser privado dos bens pré-políticos ou naturais - vida, liberdade e, relativamente, a propriedade.

Além de invioláveis ou inderrogáveis, estes direitos são também indisponíveis e inalienáveis: e é precisamente isso que os distingue de qualquer outro tipo de direito, em particular do direito de propriedade e dos outros direitos patrimoniais, que não são invioláveis enquanto não são, obviamente, inalienáveis. ${ }^{17}$

\footnotetext{
15 FERREIRA FILHO, Manoel Gonçalves. Estado de Direito e Constituição. 4 ed. São Paulo: Saraiva, 2007. p. 78.

16 SANTAMARÍA, Ramiro Ávila. Retos de una nueva institucionalidad estatal. In: SANTAMARÍA, Ramiro Ávila. Neoconstitucionalismo y Sociedad. Série Justicia Y Derechos Humanos. Quito: Ministerio de Justicia y Derechos Humanos, 2008, p. 29.
}

${ }^{17}$ FERRAJOLI, Luigi. Direito e Razão: teoria do garantismo penal. p. 794. 
LEUSIN, Rodrigo Westphalen; CADEMARTORI, Sérgio. Os direitos fundamentais nas relações privadas: da eficácia à teoria garantista de Luigi Ferrajoli. Revista Eletrônica Direito e Política, Programa de Pós-Graduação Stricto Sensu em Ciência Jurídica da UNIVALI, Itajaí, v.10, n.2, $1^{\circ}$ quadrimestre de 2015. Disponível em: www.univali.br/direitoepolitica - ISSN 1980-7791.

São, portanto, deveres do Estado de não fazer, deixar viver e deixar fazer, ou seja, prestações públicas negativas.

Para o liberalismo o termo Estado de Direito designa um "Estado legal" ou "regulado pelas leis", onde se desenvolveu o plano formal, pelo princípio da legalidade; não trata, portanto, da funcionalização substancial do Estado à garantia dos direitos fundamentais. O Estado liberal (e seu irmão mais novo, o neoliberalismo) não está (pre)ocupado com suas fontes de legitimação substancial $^{18}$.

Para o Estado liberal basta a conservação de um status pretérito, ou seja, é suficiente - garantindo a liberdade e a propriedade da classe que o propunha não piorar a situação social. As garantias liberais negativas, baseadas em vedações legais, servem para defender ou conservar condições naturais ou prépolíticas de existência: a vida, a liberdade, a imunidade aos arbítrios e, acrescente-se, a não destruição do ar, da água, do meio ambiente em geral; as garantias liberais negativas são voltadas ao passado e tem uma função conservadora $^{19}$. As instituições públicas então criadas tiveram (e têm) como principais funções, a execução das leis - portanto, a realização dos princípios liberais - a facilitação do comércio e do mercado, que com o tempo se tornaram mais complexos, constituindo-se em bancos internacionais, bolsas de valores, "sistema financeiro internacional", etc ${ }^{20}$.

O aperfeiçoamento das garantias do estado liberal ocorreu, em comparação às garantias do Estado de Direito social, de forma relativamente mais fácil: enquanto as garantias liberais exigem prestações negativas estatais consistentes no "não fazer" e por isso, conforme determinada abordagem ideológica, nada custam, as garantias sociais, por sua vez positivas, têm um custo (não maior que a sua não efetivação); enquanto os direitos liberais requerem uma posição passiva dos agentes públicos, os direitos sociais exigem uma posição ativa; em

\footnotetext{
${ }^{18}$ FERRAJOLI, Luigi. Direito e Razão: teoria do garantismo penal. p. 790.

${ }^{19}$ FERRAJOLI, Luigi. Direito e Razão: teoria do garantismo penal. p. 795.

20 SANTAMARÍA, Ramiro Ávila. Retos de una nueva institucionalidad estatal. In: SANTAMARÍA, Ramiro Ávila. Neoconstitucionalismo y Sociedad. Série Justicia Y Derechos Humanos. p. 31.
} 
LEUSIN, Rodrigo Westphalen; CADEMARTORI, Sérgio. Os direitos fundamentais nas relações privadas: da eficácia à teoria garantista de Luigi Ferrajoli. Revista Eletrônica Direito e Política, Programa de Pós-Graduação Stricto Sensu em Ciência Jurídica da UNIVALI, Itajaí, v.10, n.2, $1^{\circ}$ quadrimestre de 2015. Disponível em: www.univali.br/direitoepolitica - ISSN 1980-7791.

terceiro lugar, se a violação das públicas vedações postas em garantia dos "direitos de" dão lugar a antinomias, isto é, a normas vigentes mas inválidas, a violação das obrigações públicas postas em garantias dos "direitos a" dá lugar a lacunas, isto é, à falta de normas: e, se um antinomia pode ser resolvida com a anulação ou a reforma da norma inválida, uma lacuna pode ser apenas colmatada por meio de uma atividade normativa nem sempre facilmente coercível ou sub-rogável ${ }^{21}$.

Aqui, se por um lado o homem logrou o ideal de liberdade diante do Estado, especialmente com a implementação de um documento solene que lhe garantia formalmente uma gama de direitos - de $1^{a}$ geração - , por outro, essa garantia reduzia-se ao campo meramente formal, pois, no paradigma constitucional do Estado liberal de direito, a condição humana não melhorou muito em relação à situação pré-moderna, haja vista que a alteração aconteceu apenas no âmbito do "senhor", em quase nada alterando a condição do servo.

Em poucas palavras, tomadas da lavra do mestre italiano, "onde um ordenamento constitucional incorporar somente vedações, que requerem prestações negativas para garantia dos direitos de liberdade, este se caracteriza como Estado de direito liberal $(\ldots)^{22}$.

\section{DIREITOS FUNDAMENTAIS DE CARIZ SOCIAL: INSUFICIÊNCIA INSTITUCIONAL E DE GARANTIA PARA SUA APLICAÇÃO MEDIANTE INTERPRETAÇÃO}

Entretanto, os direitos fundamentais oriundos dos direitos sociais exigidos pela sociedade após a 2.a guerra mundial, não encontram a mesma guarida garantidora da sua efetividade e, lamentavelmente, a atuação dos operadores do direito no Brasil, em especial dos juízes (que no nosso sistema difuso de controle de constitucionalidade tem um papel relevantíssimo nesse aspecto), adotou a

\footnotetext{
${ }^{21}$ FERRAJOLI, Luigi. Direito e Razão: teoria do garantismo penal. p. 797.

${ }^{22}$ FERRAJOLI, Luigi. Direito e Razão: teoria do garantismo penal. p. 795.
} 
LEUSIN, Rodrigo Westphalen; CADEMARTORI, Sérgio. Os direitos fundamentais nas relações privadas: da eficácia à teoria garantista de Luigi Ferrajoli. Revista Eletrônica Direito e Política, Programa de Pós-Graduação Stricto Sensu em Ciência Jurídica da UNIVALI, Itajaí, v.10, n.2, 10 quadrimestre de 2015. Disponível em: www.univali.br/direitoepolitica - ISSN 1980-7791.

corrente neoconstitucionalista, impregnada por um ideário advindo do realismo jurídico anglo-saxônico.

O Estado de direito social, para além da garantia dos direitos de liberdade, incorpora como obrigações do Estado as prestações positivas para garantia dos direitos sociais.

As constituições superam o ideário liberal dos "direitos de" transmutando a posição do Estado para que garanta "direitos a", ou seja, para além dos direitos de liberdade, outros direitos, tais como à subsistência, à moradia, à saúde, à educação, à informação etc. correspondem a obrigações do estado perante o cidadão e consistem em expectativas deste ${ }^{23}$. Enquanto o Estado de Direito liberal deve, tão somente, não piorar as condições de vida dos cidadãos, o Estado de Direito social, além disso, deve melhorá-las. Essa distinção advém da diferente natureza dos bens a serem preservados: no liberalismo o estado deve preservar as condições naturais ou pré-políticas de existência, no estado social deve prover garantias sociais positivas, viabilizando ao cidadão sustentar condições sociais de vida, mediante a aquisição de subsistência, saúde, educação, trabalho, moradia, etc ${ }^{24}$.

O Estado de Direito social se expande, incluindo, além das garantias dos direitos à vida, à liberdade e à propriedade, os direitos sociais; as garantias sociais estão voltadas ao futuro e tem um caráter inovador.

Assim, modifica-se a estrutura normativa do poder estatal, para que possa cumprir o desiderato de satisfazer "direitos a" e não mais, apenas, proteger "direitos de". Não obstante, é claro e desejado, que tais diferentes modelos de estado não se excluem entre si. Todavia, também não são plenamente coerentes ou se afetam dependentemente e reciprocamente, num sentido de que a plena liberdade só poderia ser alcançada mediante o alcance da plena igualdade; ao contrário, existiram estados antiliberais, como os socialistas, ou antiliberais e

\footnotetext{
${ }^{23}$ FERRAJOLI, Luigi. Direito e Razão: teoria do garantismo penal. p. 794.

${ }^{24}$ CADEMARTORI, Sergio. Estado de Direito e Legitimidade: Uma Abordagem Garantista. 2 ed. Campinas: Millennium Editora, 2006, p. 210.
} 
LEUSIN, Rodrigo Westphalen; CADEMARTORI, Sérgio. Os direitos fundamentais nas relações privadas: da eficácia à teoria garantista de Luigi Ferrajoli. Revista Eletrônica Direito e Política, Programa de Pós-Graduação Stricto Sensu em Ciência Jurídica da UNIVALI, Itajaí, v.10, n.2, 10 quadrimestre de 2015. Disponível em: www.univali.br/direitoepolitica - ISSN 1980-7791.

antissociais, como as ditaduras da América Latina, ou estados tanto liberais como sociais, como são exemplo os estados de welfare state. ${ }^{25}$

Apesar da construção do Estado social estar evidenciada e escrita em diversas Constituições e, precipuamente, na Declaração Universal dos Direitos Humanos, tais enunciados constitucionais substanciais não estão acompanhados de garantias sociais ou positivas suficientes e adequadas para sua máxima efetivação possível.

Ao contrário do que parece e do que o senso comum permite compreender, mesmo nos avançados Welfare States, a efetivação dos direitos sociais se deu nos espaços de discricionariedade das administrações públicas, através de políticas públicas sem amparo legal vinculante, "el juego no reglado de los grupos de presión y las clientelas" ${ }^{26}$, não havendo uma elaboração aperfeiçoada de direitos sociais nas esferas legislativas infraconstitucionais, que vinculassem o Estado, no âmbito de todos os seus poderes, especialmente, no âmbito judicial, a normas positivas e subsumíveis, tal como se desenvolveu no decorrer de todo os século $X X$, em relação ao direito de propriedade, por exemplo.

Esse mesmo quadro de omissão legislativa infraconstitucional ocorre nos estados latino-americanos, tomando gravidade relevante em estados desiguais tal como - Brasil. No caso deste país, em que pese os recentes avanços em políticas sociais, com uma gradativa, mas ainda lenta diminuição das diferenças sociais e, portanto, da injustiça, muitas conquistas não estão garantidas em regras positivas lastreadas nos princípios constitucionais que as programam e que as prometem. São meras políticas de governo, suscetíveis de abandono, mediante uma simples alteração de vontade eleitoral, essa sempre sensível às manipulações de opinião e que, mesmo hoje, na hipótese de que sejam reclamadas por um cidadão a um tribunal, podem ser negadas pela desvinculação decisória do juiz frente a tais programas sócio-políticos, ou pelo mero seu ativismo judicial, interpretando e (des)aplicando princípios.

\footnotetext{
${ }^{25}$ FERRAJOLI, Luigi. Derecho y razón, 9 ed. Madrid: Trotta, 2009. p. 862.

${ }^{26}$ FERRAJOLI, Luigi. Derecho y razón, 9 ed. Madrid: Trotta, 2009. p. 862.
} 
LEUSIN, Rodrigo Westphalen; CADEMARTORI, Sérgio. Os direitos fundamentais nas relações privadas: da eficácia à teoria garantista de Luigi Ferrajoli. Revista Eletrônica Direito e Política, Programa de Pós-Graduação Stricto Sensu em Ciência Jurídica da UNIVALI, Itajaí, v.10, n.2, $1^{\circ}$ quadrimestre de 2015. Disponível em: www.univali.br/direitoepolitica - ISSN 1980-7791.

Parece, portanto, ser nesse espaço vazio havido entre as normas constitucionais que definem os direitos sociais como princípios e a ausência de legislações positivas e subsumíveis, que se encontra o campo fértil para a desdiferenciação dos poderes de estado, para sua deslegitimação, para a crise do direito e, portanto, da política.

\section{RECUPERAÇÃO DO JUSNATURALISMO OU CONSAGRAÇÃO DO POSITIVISMO VIA GARANTISMO PARA EFETIVAR DIREITOS FUNDAMENTAIS}

As Cartas do constitucionalismo contemporâneo garantem as esferas políticas dos cidadãos, limitando o poder do estado tanto internamente quanto externamente. Também garantem os direitos civis, acolhendo-os de uma tradição liberal que há muito os garante, com base em culturas (saber), instituições e direito consolidados positivados.

As constituições contemporâneas também definem os direitos sociais de modo universal, programando o desenvolvimento de um estado mais complexo, provedor desses direitos. Até cria instrumentos, como o Mandado de Injunção, para que se obrigue o Estado legislador a positivar as regras necessárias para sua efetivação.

Todavia, a cultura e o saber, as instituições e o direito hoje consolidados teimam em não avançar em prol da realização desse Estado Constitucional Democrático, porque ainda arraigados e apoderados nas pretensões burguesas sete e oitocentistas, situação que provoca a crise do Estado e, portanto, do Direito, deslegitimando-o pela inefetividade em concretizar, mesmo no mínimo necessário, os direitos sociais.

Cria-se então um espaço de omissão, entre os princípios constitucionais e a ausência das regras de suas efetivações, onde inserem-se outros poderes. Parcela desse espaço é ocupada pelo Poder Judiciário, que através da concepção neoconstitucionalista, vê-se dotado de uma pretensa legitimidade para criar o 
LEUSIN, Rodrigo Westphalen; CADEMARTORI, Sérgio. Os direitos fundamentais nas relações privadas: da eficácia à teoria garantista de Luigi Ferrajoli. Revista Eletrônica Direito e Política, Programa de Pós-Graduação Stricto Sensu em Ciência Jurídica da UNIVALI, Itajaí, v.10, n.2, $1^{\circ}$ quadrimestre de 2015. Disponível em: www.univali.br/direitoepolitica - ISSN 1980-7791.

direito, a partir do caso concreto até o nível de controle de constitucionalidade (controle concentrado e difuso de constitucionalidade), através da assimilação de que os princípios constitucionais são o sucedâneo dos princípios gerais do direito ou como sendo o "suporte dos valores da sociedade"27.

A incorporação de valores superiores nas constituições contemporâneas, estabelecidos em direitos fundamentais (incluindo-se, evidentemente, os direitos sociais) considerados como princípios, motiva os autores neoconstitucionalistas a asseverar a extinção, ou pelo menos, a superação, de uma das premissas do juspositivismo: a tese da separação entre direito e moral. Além disso, uma característica do neoconstitucionalismo é a concepção dos direitos fundamentais como princípios em constante colisão, de tal sorte que as técnicas de argumentação para solução dos conflitos principiológicos, adotadas pelos magistrados, assumiram centralidade para essa concepção ${ }^{28}$.

Dessarte, esse posicionamento do magistrado, adotando 0 ideário neoconstitucionalista, deslocou a principal fonte do direito; agora não mais a lei, mas sim a decisão judicial. O exercício das técnicas de argumentação, tal como o uso da ponderação, substitui a racionalidade legislativa. E essa posição, reforçando a relegação e a omissão da atividade parlamentar ao segundo plano, implica o enfraquecimento e a consolidação dos direitos sociais a "genéricas recomendações ético-políticas"29.

27 STRECK, Lênio. In: FERRAJOLI, Luigi. STRECK, Lênio. TRINDADE, Karam André. ROSA, Alexandre Morais. NETO, Copetti Alfredo. STRAPAZZON, Luiz Carlos. ADEODATO, João Maurício. OLIVEIRA DE, Rafael Tomaz. CADEMARTORI, Sérgio (Orgs.). Garantismo, hermenêutica e (neo) constitucionalismo: um debate com Luigi Ferrajoli. Porto Alegre: Livraria do Advogado, 2012. p. 11.

28 CADEMARTORI, Sergio. In: FERRAJOLI, Luigi. STRECK, Lênio. TRINDADE, Karam André. ROSA, Alexandre Morais. NETO, Copetti Alfredo. STRAPAZZON, Luiz Carlos. ADEODATO, João Maurício. OLIVEIRA DE, Rafael Tomaz. CADEMARTORI, Sérgio (Orgs.). Garantismo, hermenêutica e (neo) constitucionalismo: um debate com Luigi Ferrajoli. Porto Alegre: Livraria do Advogado, 2012. p. 256.

${ }^{29}$ CADEMARTORI, Sergio. In: FERRAJOLI, Luigi. STRECK, Lênio. TRINDADE, Karam André. ROSA, Alexandre Morais. NETO, Copetti Alfredo. STRAPAZZON, Luiz Carlos. ADEODATO, João Maurício. OLIVEIRA DE, Rafael Tomaz. CADEMARTORI, Sérgio (Orgs.). Garantismo, hermenêutica e (neo) constitucionalismo: um debate com Luigi Ferrajoli. Porto Alegre: Livraria do Advogado, 2012. p. 257. 
LEUSIN, Rodrigo Westphalen; CADEMARTORI, Sérgio. Os direitos fundamentais nas relações privadas: da eficácia à teoria garantista de Luigi Ferrajoli. Revista Eletrônica Direito e Política, Programa de Pós-Graduação Stricto Sensu em Ciência Jurídica da UNIVALI, Itajaí, v.10, n.2, $1^{\circ}$ quadrimestre de 2015. Disponível em: www.univali.br/direitoepolitica - ISSN 1980-7791.

A redução, portanto, dos direitos fundamentais sociais à princípios ético-políticos, originados de argumentos morais, degenera a força vinculante que tais direitos deveriam possuir, tal como foi atribuída aos direitos civis liberais. Enquanto deveriam servir aos juízes como argumento de provocação do parlamento para que concretizassem tais princípios em regras subsumíveis - o que também provocaria, necessariamente, o aperfeiçoamento das instituições de garantia para efetivá-los - os direitos fundamentais, especialmente os de cariz social, tornam-se meras invenções normativas, neutralizados como se fossem princípios ético-políticos de criação jurisprudencial.

Sendo assim, a Jurisprudência e a Ciência Jurídica, apoderada da criação da legislação em detrimento do Parlamento, reassume a posição de fonte suprema do direito, representando uma espécie de regressão ao direito jurisprudencial pré-moderno. ${ }^{30}$

Noutro aspecto, o neoconstitucionalismo, sufocando a já fraca pretensão legiferante em relação aos direitos sociais, pressupõe como dito alhures, para justificar-se, o afastamento da distinção necessária entre direito e moral, pois no próprio ordenamento jurídico já existiria uma "pretensão de justiça", um "mínimo ético", onde os princípios constitucionais seriam objetivamente justos, portanto, desprezando a necessidade de que sejam convertidos em regras subsumíveis, ou, pelo menos, democraticamente criadas pelo Parlamento. Conforme ensina Ferrajoli, isso significa, em suma, o mesmo que a velha tese jusnaturalista, contrária, oposta a tese juspositivista da separação entre direito e moral, "segundo a qual a existência ou a validade de uma norma não implicam, de modo algum, a justiça, da mesma forma como a sua justiça não implica, de modo algum, a sua validade ${ }^{\prime 31}$.

30 FERRAJOLI, Luigi. In: FERRAJOLI, Luigi. STRECK, Lênio. TRINDADE, Karam André. ROSA, Alexandre Morais. NETO, Copetti Alfredo. STRAPAZZON, Luiz Carlos. ADEODATO, João Maurício. OLIVEIRA DE, Rafael Tomaz. CADEMARTORI, Sérgio (Orgs.). Garantismo, hermenêutica e (neo) constitucionalismo: um debate com Luigi Ferrajoli. Porto Alegre: Livraria do Advogado, 2012. p. 38.

${ }^{31}$ FERRAJOLI, Luigi. Direito e Razão: teoria do garantismo penal. p. 855. 
LEUSIN, Rodrigo Westphalen; CADEMARTORI, Sérgio. Os direitos fundamentais nas relações privadas: da eficácia à teoria garantista de Luigi Ferrajoli. Revista Eletrônica Direito e Política, Programa de Pós-Graduação Stricto Sensu em Ciência Jurídica da UNIVALI, Itajaí, v.10, n.2, $1^{\circ}$ quadrimestre de 2015. Disponível em: www.univali.br/direitoepolitica - ISSN 1980-7791.

A separação entre direito e moral, além de fundamento do próprio liberalismo e da própria democracia constitucional, também por isso é pressuposto do reconhecimento e premissa do pluralismo moral, ideológico e cultural.

Ademais, a defesa da separação entre direito e moral (e a negação do cognitivismo ético) é, outrossim, a principal garantia da submissão dos magistrados à lei. Todavia, esse pressuposto do Garantismo, que é a separação entre direito moral, não ignora a abordagem da moral e do político sobre o direito; na verdade, ele estabelece a sua autonomia, "mas também o primado do ponto de vista jurídico interno como do ponto de vista da crítica externa, da projeção e da transformação institucional; e, ainda, se a lei é considerada intoleravelmente imoral, como fundamento do dever moral à desobediência civil", porque, nesse caso último, a moral não está atrelada à obediência à lei que o Direito supõe $\mathrm{e}^{32}$.

Observe-se, então, que dentre as divergências decorrentes da confusão oriunda da concepção neoconstitucional entre validade e justiça, validade e vigência e vigência e eficácia, a divergência entre o "dever ser constitucional" e o "ser" legislativo do direito, não pode ser reparada através da argumentação moral e pela ponderação judicial. Não pode o juiz "colmatar" as "lacunas estruturais" e suprir a interposição da legislação advinda do Parlamento democraticamente eleito para introduzir a garantia da efetividade.

A efetividade do Direito em toda sua amplitude constitucional carece, portanto, de que os papeis atribuídos a cada poder do estado sejam exercidos independentemente, conforme suas funções constitucionalmente definidas, sob pena da precariedade do alcance das garantias desses direitos (e do próprio objeto de direito, portanto) e, também, da violação dos princípios liberais e democráticos, tal como a separação dos poderes.

32 FERRAJOLI, Luigi. In: FERRAJOLI, Luigi. STRECK, Lênio. TRINDADE, Karam André. ROSA, Alexandre Morais. NETO, Copetti Alfredo. STRAPAZZON, Luiz Carlos. ADEODATO, João Maurício. OLIVEIRA DE, Rafael Tomaz. CADEMARTORI, Sérgio (Orgs.). Garantismo, hermenêutica e (neo) constitucionalismo: um debate com Luigi Ferrajoli. Porto Alegre: Livraria do Advogado, 2012. p. $20 / 1$. 
LEUSIN, Rodrigo Westphalen; CADEMARTORI, Sérgio. Os direitos fundamentais nas relações privadas: da eficácia à teoria garantista de Luigi Ferrajoli. Revista Eletrônica Direito e Política, Programa de Pós-Graduação Stricto Sensu em Ciência Jurídica da UNIVALI, Itajaí, v.10, n.2, $1^{\circ}$ quadrimestre de 2015. Disponível em: www.univali.br/direitoepolitica - ISSN 1980-7791.

Entretanto, no positivismo constitucional garantista, a reparação decorrente da violação de direito fundamental entre particulares, também é atribuída ao juiz, pois é natural que os juízes, dentro dos seus espaços fisiológicos, interpretem a lei conforme a Constituição, mas tão somente ampliando ou restringindo o seu alcance. Podem mesmo aplicar diretamente a norma constitucional nos casos que não exigem a regulamentação legal inferior, e nesse aspecto é que se inclui a importância significativa da técnica da cláusula geral.

Mas, deve-se ter em mente que a ponderação judicial não é um princípio de per si, ou um valor a ser considerado; é apenas, conforme ensina J. J. Gomes Canotilho33, "um elemento do procedimento da interpretação/aplicação de normas conducente à atribuição de um significado normativo e à elaboração de uma norma de decisão".

Ainda que para alguns doutrinadores do direito constitucional as diferenças entre normas e princípios sejam mais profundas do que para Luigi Ferrajoli, a classificação de J. J. Gomes Canotilho a respeito da eficácia da norma fundamental na relação entre privados mediada pelo magistrado é bastante esclarecedora quanto ao papel do juiz na aplicação do direito fundamental ${ }^{34}$ :

a) Em primeiro lugar, devem fazer uma aplicação do direito privado legalmente positivado em conformidade com os direitos fundamentais pela via da interpretação conforme a constituição.

b) Se a interpretação conforme os direitos, liberdades e garantias for insuficiente cabe sempre na competência dos tribunais a desaplicação da lei (por inconstitucional) violadora dos direitos (subjectivos) ou dos bens constitucionalmente garantidos pelas normas consagradoras de direitos fundamentais.

c) A interpretação conforme os direitos, liberdades e garantias das normas de direito privado utilizará como instrumentos metódicos não apenas as clássicas cláusulas gerais ou conceitos indeterminados (ex.: boa fé, abuso de direito) mas também as próprias normas consagradoras e

\footnotetext{
33 CANOTILHO, José Joaquim Gomes. Direito Constitucional e Teoria da Constituição. p. 1236.

34 CANOTILHO, José Joaquim Gomes. Direito Constitucional e Teoria da Constituição. Coimbra: Edições Almedina, 7.a edição (2.a reimpressão), 2006, p. 1292.
} 
LEUSIN, Rodrigo Westphalen; CADEMARTORI, Sérgio. Os direitos fundamentais nas relações privadas: da eficácia à teoria garantista de Luigi Ferrajoli. Revista Eletrônica Direito e Política, Programa de Pós-Graduação Stricto Sensu em Ciência Jurídica da UNIVALI, Itajaí, v.10, n.2, $1^{\circ}$ quadrimestre de 2015. Disponível em: www.univali.br/direitoepolitica - ISSN 1980-7791.

defensoras dos bens jurídicos absolutos (vida, liberdade). Trata-se, pois, de uma concretização de bens jurídicos constitucionalmente protegidos através de normas de decisão judiciais (captadas ou extrinsecadas por interpretação-integração pelo direito judicial.

O modelo proposto por Canotilho demonstra-se extremamente adaptado a um procedimento de aplicação de normas e princípios, ainda mais quando tomada em conta a ideia de Ferrajoli a respeito da indiferença substancial existente entre princípios e regras. O problema que surge e afeta o sistema brasileiro é que nos países europeus de modelo romano-germânico os tribunais constitucionais, que dão a última palavra a respeito da efetivação do direito consagrado em norma fundamental constitucional, são tribunais compostos também por juízes eleitos na via democrática, incluindo-se indivíduos escolhidos por instituições do povo, o que não ocorre na eleição dos ministros do STF.

\section{CONSIDERAÇÕES FINAIS}

A posição exarada por diversos autores de cariz neoconstitucional, adotando critérios (fortemente subjetivos) de ponderação de regras (como se as regras não portassem um forte caráter principiológico e valorativo) e princípios (como se os princípios não portassem um forte caráter regulatório), pode, através da técnica das cláusulas gerais, aplicar ou não, decidir ou não, determinado caso, conforme seu juízo a priori.

Alega-se, não sem razão, que o ideário garantista, que implicaria uma produção legislativa total, confunde-se com o desejo positivista de regular todas as dimensões relacionais humanas, o que constituiu um desafio intransponível.

Porém, também não deixa de ser enormemente desafiadora a tarefa de estabelecimento de critérios de ponderação, nas hipóteses de conflitos de normas, pois o agente violador também é titular em si de direitos fundamentais.

De outro lado, as possibilidades de aplicação e efetivação dos direitos fundamentais nas relações privadas têm constituído uma temática profunda e 
LEUSIN, Rodrigo Westphalen; CADEMARTORI, Sérgio. Os direitos fundamentais nas relações privadas: da eficácia à teoria garantista de Luigi Ferrajoli. Revista Eletrônica Direito e Política, Programa de Pós-Graduação Stricto Sensu em Ciência Jurídica da UNIVALI, Itajaí, v.10, n.2, $1^{\circ}$ quadrimestre de 2015. Disponível em: www.univali.br/direitoepolitica - ISSN 1980-7791.

inesgotável para o aperfeiçoamento das doutrinas jurídicas e jusfilosóficas atinentes à matéria.

A ânsia de propor e encontrar o melhor modelo, entretanto, deve compor as soluções mais racionais de cada possibilidade técnica, o que geralmente será encontrado diante do caso concreto - ainda que pareça o ideal, a completude do sistema jurídico/judicial, especialmente no caso brasileiro, parece que nunca esteve tão distante de uma sociedade que se demonstra cada vez mais complexa, heterogênea e de atores cada vez mais ativos (nem sempre com base em preceitos justos, racionais e democráticos).

Coloca-se, então, como desafio interminável do Direito buscar as melhorias das relações humanas, vinculando a política e a Justiça.

\section{REFERÊNCIAS DAS FONTES CITADAS}

ARONNE, Ricardo. Por uma nova hermenêutica dos Direitos Reais limitados: das raízes aos fundamentos contemporâneos. Rio de Janeiro: Renovar, 2001.

CADEMARTORI, Sergio. Estado de Direito e Legitimidade: Uma Abordagem Garantista. 2. a ed. atualizada e ampliada. Campinas, SP: Millennium Editora, 2006.

CANOTILHO, José Joaquim Gomes. Direito Constitucional e Teoria da Constituição. Coimbra: Edições Almedina, 7.a edição (2.a reimpressão), 2006. COMPARATO, Fábio Konder. Ética, direito, moral e religião no mundo moderno. 2.a ed. rev. São Paulo: Companhia das letras, 2008.

A afirmação história dos direitos humanos. 7.a edição. 3.a tiragem. São Paulo: Saraiva, 2011. 
LEUSIN, Rodrigo Westphalen; CADEMARTORI, Sérgio. Os direitos fundamentais nas relações privadas: da eficácia à teoria garantista de Luigi Ferrajoli. Revista Eletrônica Direito e Política, Programa de Pós-Graduação Stricto Sensu em Ciência Jurídica da UNIVALI, Itajaí, v.10, n.2, 10 quadrimestre de 2015. Disponível em: www.univali.br/direitoepolitica - ISSN 1980-7791.

DÜRIG, Günter. NIPPERDEY, Hans Carl. SCHWABE, Jurgen. Direitos fundamentais e direito privado. Textos clássicos. Porto Alegre: Sergio Fabris Editor, 2012.

FACHIN, Luiz Edson. Teoria Crítica do Direito Civil à luz do novo Código Civil Brasileiro. 3. a edição. Rio de Janeiro: Renovar, 2003.

FERRAJOLI, Luigi. Direito e Razão: teoria do garantismo penal. 2.a ed. rev. e ampl. Tradução: Ana Paula Zomer Sica. São Paulo: Editora Revista dos Tribunais, 2006.

. Democracia y garantismo. Edición de Miguel Carbonell. Madrid: Editorial Trotta, 2008.

Por uma Teoria dos Direitos e dos Bens Fundamentais. Edição digital. Tradução: Alexandre Salim, Alfredo Copetti Neto, Daniela Cademartori, Hermes Zaneti Júnior, Sérgio Cademartori. Porto Alegre: Livraria do Advogado, 2011.

Garantismo, hermenêutica e (neo) constitucionalismo: um debate com Luigi Ferrajoli. Organizadores Luigi Ferrajoli, Lenio Luiz Streck, André Karam Trindade, Alexandre Morais da Rosa, Alfredo Copetti Neto, Carlos Luiz Strapazzon, João Maurício Adeodato, Rafael Tomaz de Oliveira, Sérgio Cademartori. Porto Alegre: Livraria do Advogado, 2012.

Derecho y razón, 9.a ed. Madrid, Trotta, 2009.

FERREIRA FILHO, Manoel Gonçalves. Estado de Direito e Constituição. 4.a edição revista e atualizada. São Paulo: Saraiva, 2007.

GRAU, Eros Roberto. O Direito Posto e o Direito Pressuposto. 6. a edição revista e ampliada. São Paulo: Malheiros Editores, 2005.

PIOVESAN, Flávia. Direitos humanos e o direito constitucional internacional. 14. a edição. São Paulo: Saraiva, 2013. 
LEUSIN, Rodrigo Westphalen; CADEMARTORI, Sérgio. Os direitos fundamentais nas relações privadas: da eficácia à teoria garantista de Luigi Ferrajoli. Revista Eletrônica Direito e Política, Programa de Pós-Graduação Stricto Sensu em Ciência Jurídica da UNIVALI, Itajaí, v.10, n.2, $1^{\circ}$ quadrimestre de 2015. Disponível em: www.univali.br/direitoepolitica - ISSN 1980-7791.

SANTAMARÍA, Ramiro Ávila. Retos de una nueva institucionalidad estatal. In Neoconstitucionalismo y Sociedad, org. Ramiro Ávila Santamaria. 1.a edição. Série Justicia Y Derechos Humanos, Quito: Ministerio de Justicia y Derechos Humanos, 2008.

SARLET, Ingo Wolfgang. A Eficácia dos Direitos Fundamentais. 11. a edição. Porto Alegre: Editora Livraria do Advogado, 2012.

STRECK, Lênio Luiz / MORAIS, José Luiz Bolzan. Ciência política e teoria do estado. 7. a edição. Porto Alegre: Editora Livraria do Advogado, 2010.

TEPEDINO, Gustavo / FACHIN, Luiz Edson. Org. Diálogos sobre o Direito Civil - volume II, Rio de Janeiro: Renovar, 2008.

Submetido em: Março/2015

Aprovado em: Abril/2015 